\title{
Fate of river Tiber discharge investigated through numerical simulation and satellite monitoring
}

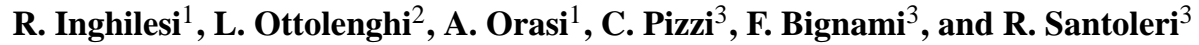 \\ ${ }^{1}$ Institute for Environmental Protection and Research (ISPRA), Italy \\ ${ }^{2}$ University of Roma Tre, Italy \\ ${ }^{3}$ Institute of Atmospheric Sciences and Climate of the Italian National Research Council - Satellite Oceanography Group \\ (ISAC/CNR-GOS), Italy
}

Correspondence to: R. Inghilesi (roberto.inghilesi@isprambiente.it)

Received: 1 March 2012 - Published in Ocean Sci. Discuss.: 12 April 2012

Revised: 10 August 2012 - Accepted: 15 August 2012 - Published: 18 September 2012

\begin{abstract}
The aim of this study was to determine the dispersion of passive pollutants associated with the Tiber discharge into the Tyrrhenian Sea using numerical marine dispersion models and satellite data. Numerical results obtained in the simulation of realistic discharge episodes were compared with the corresponding evolution of the spatial distributions of MODIS diffuse light attenuation coefficient at $490 \mathrm{~nm}$ (K490), and the results were discussed with reference to the local climate and the seasonal sub-regional circulation regime. The numerical model used for the simulation of the sub-tidal circulation was a Mediterranean sub-regional scale implementation of the Princeton Ocean Model (POM), nested in the large-scale Mediterranean Forecasting System. The nesting method enabled the model to be applied to almost every area in the Mediterranean Sea and also to be used in seasons for which imposing climatological boundary conditions would have been questionable. Dynamical effects on coastal circulation and on water density due to the Tiber discharge were additionally accounted for in the oceanographic model by implementing the river estuary as a point source of a buoyant jet. A Lagrangian particle dispersion model fed with the POM current fields was then run in order to reproduce the effect of the turbulent transport of passive tracers mixed in the plume with the coastal flow. Two significant episodes of river discharge in both winter and summer conditions were discussed in this paper. It was found that the winter regime was characterized by the presence of a strong coastal jet flowing with the ambient current. In summer the prevailing wind regime induced coastal downwelling conditions, which tended to confine the riverine waters close to the
\end{abstract}

shore. In such conditions sudden wind reversals due to local weather perturbations, causing moderate local upwelling, proved to be the only effective way to disperse the tracers offshore, moving the plume from the coast and detaching large pools of freshwater.

\section{Introduction}

Most pollution of the coastal marine environment is associated with river runoff, which carries into the sea the effects of atmospheric pollution and human urban, agricultural and industrial wastes. The effects of the so-called nonpoint sources of pollution are the presence in the water of high concentration of pathogens, oxygen-depleting nutrients and many toxic substances such as heavy metals and PCBs. The Tiber, the third longest Italian river, crosses two Italian regions well known for their agricultural and farming activities, and then flows through Rome just before entering the central Tyrrhenian Sea. Even though Tiber discharge rarely exceeds $200 \mathrm{~m}^{3} \mathrm{~s}^{-1}$ in summer, several occurrences of rapid floods have been reported to be associated with the death of most of the fish present in the final course of the river, due to the sudden depletion of oxygen in the water. Concentrations of bacteria and viruses at the river mouth are also a matter of primary concern for public health, thus potentially affecting tourism at the many coastal resorts in the central and upper Tyrrhenian Sea. It is therefore important to assess the potential impact of pollutants carried in the river's fresh waters, as 
well as that of the sediments transported to the marine and the coastal environment.

Even though practical considerations often lead the investigators inclined to treat the dispersion of pollutants in coastal areas as a local diffusion problem, in reality, most of the time it is not. The interaction between riverine freshwater and ambient saline water in estuaries has been studied by means of shallow water and primitive equation models in idealized and more realistic conditions. It was found that the dynamical scales of motion which are involved in the problem range from a local scale, i.e. a few tens of meters to some kilometers (where the geometry of the estuary, the discharge and the local wind are essential factors), to more than $100 \mathrm{~km}$ (where persistent mesoscale features like gyres and jets embed the riverine plume in a complex, large-scale structure extending in a typical meandering jet flowing along or detached from the coast). Dynamical processes at different scales interact, as, for example, when a change in wind direction induces a secondary coastal circulation leading to upwelling or downwelling episodes. Dispersion would then depend on the local and the large-scale circulation, while the wind and the currents could be oriented parallel or antiparallel to the coastal jet.

Important aspects of the problem on a local scale are the dynamics associated with the discharge of light freshwater in a denser ambient flow, the presence of currents and tides, the speed and direction of the wind, the concentration of pollutants in the river and the amount of volumetric discharge. The first of the foregoing factors has been investigated by several authors. Generally speaking, the forcing operated by the freshwater on the ambient flow can be interpreted in terms of a classical Rossby geostrophic adjustment problem (Hsieh and Gill, 1983). As shown by Garvine (1987), rotation is a key factor in the dynamics of the plume. Even for small estuaries, the Coriolis acceleration greatly modifies the density fields and the currents at considerable distances from the river mouth. The characteristic scales of the problem are the width of the estuary, $L_{q}$, and the Rossby radius of deformation for the first baroclinic mode, $R_{0}$. The ratio of the two lengths is known as the Kelvin number, $K=L_{q} / R_{0}$. The value of $K$ is an indication of the distance from the source at which the effect of the rotation becomes important. Closer to the source and up to distances of the order of $K$ Rossby radiuses (in the "near field flow", in stagnant uniform ambient), there are other length scales which define the aspect of the buoyant jet. These are related to the relative importance of the discharge momentum flux $M=u_{0} Q_{0}$ ("jetlike" flow behavior close to the source where $M$ is prevailing) with respect to the discharge buoyancy flux $B=g^{\prime} Q_{0}$ ("plumelike" flow behavior where $B$ dominates, towards the far field). $Q_{0}$ is the river discharge rate in $\mathrm{m}^{3} \mathrm{~s}^{-1}$ and $u_{0}$ is the average cross-section flow velocity. The distance at which the flow becomes plumelike can be estimated by means of the non-dimensional length $L_{\mathrm{m}}=\frac{M^{3 / 4}}{\sqrt{B}}$. Depending on the value of the Froude number $F=q / c$ - where $c=\sqrt{g^{\prime} d_{0}}$ is the phase speed of the internal long gravity waves depending on reduced gravity $g^{\prime}=\delta \rho / \rho$ and surface layer thickness $d_{0}$, and $q$ is the horizontal speed - the far field flow can be supercritical or subcritical. An accurate description of the dynamics of supercritical flows can be found in Garvine (1987); Chao (1987); and Oey (1996). In particular, the formation of the discharge front at the river mouth and a coastal front bounding a coastal jet downstream, which eventually become unstable and start meandering, is clearly described in Garvine (1987) and Oey and G.L.Mellor (1992). Following the classification of Chao (1987) revisited by Kourafalou et al. (1996a), in a supercritical flow the dimension of the bulge at the estuary mouth greatly exceeds the width of the coastal jet downstream, while in subcritical flows the two amplitudes are at least comparable. The jet can also divert from the coastline (after long time periods) forming an anticyclonic gyre. While in supercritical flows all disturbances (Kelvin waves and internal waves) propagate downstream, in subcritical flows long gravity wave perturbations can propagate upstream in the region where $F<1$. A discrimination between supercritical and subcritical flows was introduced by Garvine (1987) in terms of the transport parameter $\tau=T f /\left(2\left(g^{\prime} d_{0}\right)^{2}\right)$ and the angle made by the estuary with the coastline. Here, $T$ is river discharge and $f$ is the Coriolis parameter. In the case of the Tiber, the angle is close to $90^{\circ}$ and $\tau$ ranges between 0.001 in typical summer conditions (discharge $T=140 \mathrm{~m}^{3} \mathrm{~s}^{-1}$ ) and 0.03 in the case of significant winter discharges $\left(T>1000 \mathrm{~m}^{3} \mathrm{~s}^{-1}\right)$, so the plume will behave as supercritical for $T<1000 \mathrm{~m}^{3} \mathrm{~s}^{-1}$ but can be subcritical during episodes of strong river discharge. An equivalent discrimination was introduced and discussed by García Berdeal et al. (2002) in terms of $\lambda=L_{\mathrm{B}} / L_{\mathrm{C}}$, where $L_{\mathrm{B}}$ is the size of the far field bulge and $L_{C}$ is the width of the coastal jet (Kourafalou et al., 1996a). Finally, several numerical studies (Chao, 1988; Fong and Geyer, 2001; García Berdeal et al., 2002) have pointed out how the characteristics of the plume are considerably modified by the action of the coastal ambient current and the wind. Situations favorable to downwelling lead to the presence of a meandering of the coastal jet, while the presence of upwelling might detach the coastal jet from the coast.

The dispersion of the riverine waters was studied using a three-dimensional, primitive-equation, oceanographic model described in Sect. 3, coupled with a particle Lagrangian transport model (Sects. 3.2 and 3.3) in order to simulate the transport of a passive tracer associated with the river discharge. The evolution of the river plume over time was also tracked using remote sensing observations of diffuse light attenuation coefficient at $490 \mathrm{~nm}$ (K490; Sect. 2). This quantity has proven to be a very effective tracer for detecting turbid coastal waters, even though quantitatively it is not reliable in such waters (Case II waters, Morel and Prieur, 1977), as is the case for most ocean color algorithms (e.g. chlorophyll). The method was tested on several key studies in summer and 
winter conditions (Sect. 4). The comparisons of the results of numerical simulations and remote sensing observations indicate the strengths and the weaknesses of both the analyses, providing information on how to make the best use of them in environmental monitoring (Sect. 5).

\section{The implementation of the ICE-POM model}

The numerical simulations of the Tyrrhenian Sea currents were made using the ISPRA Coastal and Estuarine Princeton Ocean Model (ICE-POM) model. The POM (Mellor, 2004; Blumberg and Mellor, 1987) is a three-dimensional model which solves the primitive equations in hydrostatic and Boussinesq approximation. The grid has sigma coordinates on the vertical and is formulated on the Arakawa Cgrid, following latitude and longitude on the horizontal. Despite the fact of having variable depths in the domain and vertical velocity defined on sigma-planes, sigma coordinates are especially useful in situations of complex bottom topography, as is the case with the Tyrrhenian Sea. The numerics of the model allows the separation of fast barotropic (external) modes, i.e. sea level and vertically averaged velocity, and (internal) baroclinic modes for salinity, temperature and 3-D velocity fields. The model has been one-way nested in the domain of the Ocean PArallelise-Mediterranean Ocean Forecasting System (OPA/MFS) (Pinardi et al., 2003; Oddo et al., 2009). The open boundaries were located in the Sicily Channel, the Sardinia Channel and the Corsica Strait, as shown in Fig. 1a. The MFS daily analysis fields, at $1 / 16 \times 1 / 16$ degree horizontal resolution and 72 unevenly spaced vertical levels, were kindly provided by the Italian Istituto Nazionale di Geofisica e Vulcanologia (INGV) in the framework of the MyOcean project. The nesting allows the ICE-POM to be implemented almost everywhere in the Mediterranean Sea, in any season and meteorological condition. The model grid used had $375 \times 300$ nodes with 32 sigma vertical levels. The horizontal dimension of the grid cells was close to $2.0 \times 2.0 \mathrm{~km}$. The vertical size of the cells was linear in the central 26 levels, logarithmically distributed in the top 4 and in the 2 bottom cells. The time step for the external mode was set to $6.0 \mathrm{~s}$ at the beginning of the spin-up period, and reduced to $1 \mathrm{~s}$ during discharge episodes exceeding $600 \mathrm{~m}^{3} \mathrm{~s}^{-1}$. The ratio between external and internal mode was set to 40 .

\subsection{Boundary conditions}

Lateral boundary conditions (BC) were imposed at the open boundaries shown in Fig. 1a, while, at the surface, heat flux and wind stress forcings were considered. The usual conditions of no fluxes, no slip velocity were applied at the bottom. Initial and lateral conditions at the open boundaries were extracted from the daily analyses of the OPA/MFS model. The open boundaries were selected in order to facilitate the onset of the specific kind of circulation known in the Central

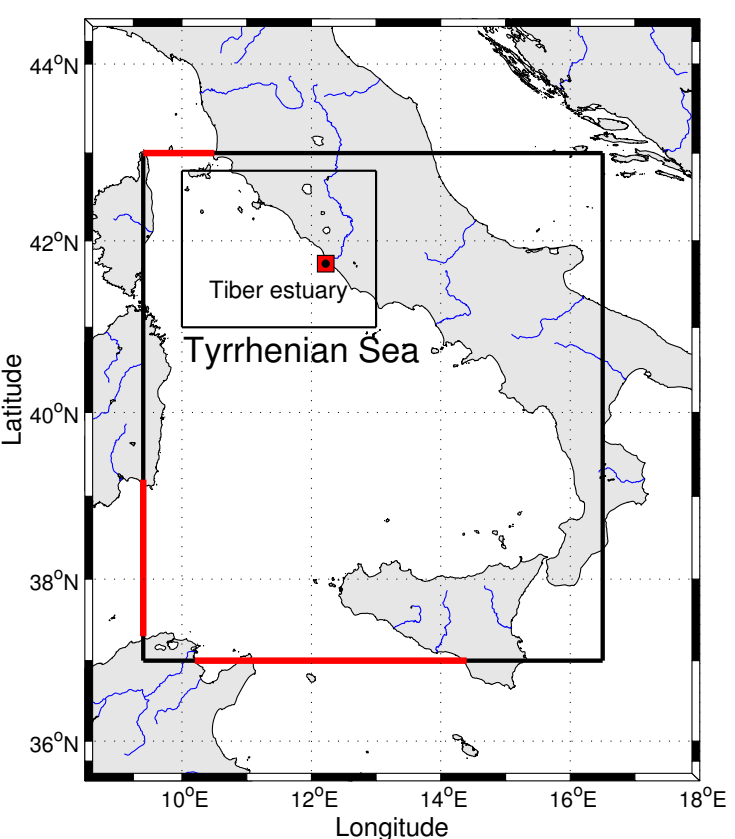

(a)

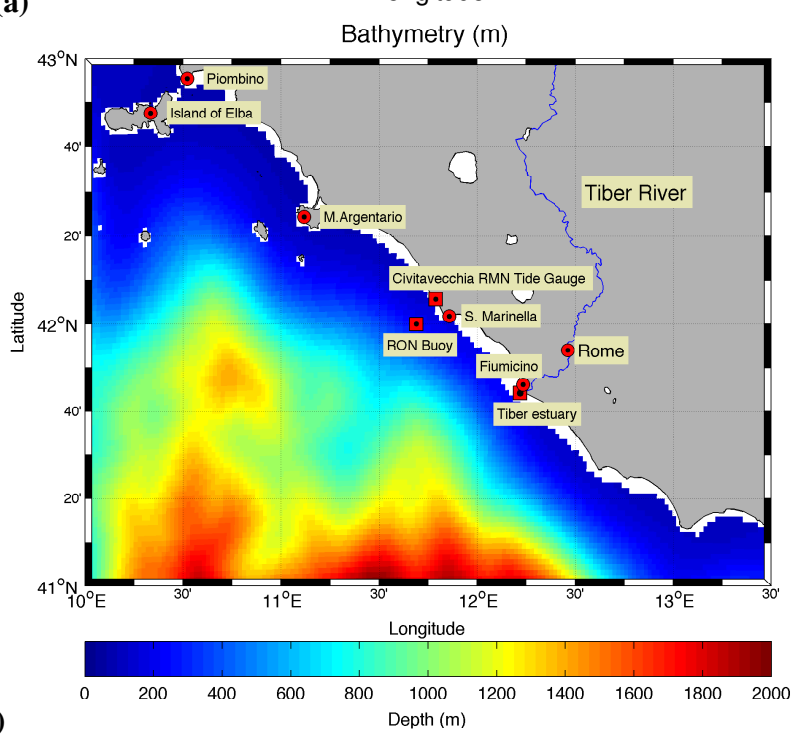

(b)

Fig. 1. (a) Outer black box: domain of the numerical simulation (open boundaries are in red). Small internal box is expanded in (b). (b) Map of the bathymetry north of the Tiber Estuary. The positions of the meteorological onshore and offshore stations are marked with a red box.

Mediterranean region, see Vetrano et al. (2004) and Pinardi and Masetti (2000), and specifically in the Tyrrhenian Sea. In fact, the sub-regional dynamics of the Tyrrhenian Sea are strongly dependent on the inflow of Modified Atlantic Water (MAW) from the Sardinia Channel and the inflow of Levantine Intermediate Water (LIW) from the Sicily Channel, at least in winter, while the system typically decouples from the rest of the Mediterranean Basin from summer to early fall. At the open boundaries Flather-type BC were implemented on the barotropic velocities following Palma and 
Matano (2001). Inward flows of baroclinic (internal) fields of temperature, salinity, 3-D velocities and turbulence were "clamped" to the MFS fields with a relaxation period of $24 \mathrm{~h}$. In the case of internal mode fields directed outward, radiative BC were used. The coupling of the ICE-POM with the MFS fields was made every day at 12:00. At the surface, the wind stress forecasted by the ISPRA Hydro-Marine and Meteorological System (Speranza et al., 2004; Bargagli et al., 2002) was used. The meteorological model used to simulate the wind was the BOLAM model (Buzzi et al., 1994) nested in the ECMWF global domain in the Mediterranean Sea. The BOLAM nesting into ECMWF provided consistency between the BOLAM and the OPA/MFS forcings on the ICEPOM. The wind at $10 \mathrm{~m}$ had a resolution of $0.1 / 0.1$ degrees and was available every $3 \mathrm{~h}$. Salinity at the surface was forced by the corresponding MSF field every day, except at the river estuary. Sea surface temperature was forced by daily satellite observations provided by MyOcean (MED CNR Sea Surface Temperature L3S), as described in Buongiorno-Nardelli et al. (2012). As is well known, the POM is based on the MellorYamada level 2.5 closure scheme, described in Mellor and Jamada (1974). Here a value of HORCON $=0.2$ for the Smagorinsky horizontal diffusivity coefficient, TPRNI $=0.2$ as the inverse horizontal turbulent Prandtl number (Ah / Am), and nmol $=2 \times 10^{-5}$ for the background viscosity were used.

\subsection{River implementation - Eulerian dispersion}

The Tiber estuary is relatively small (width $L_{q} \cong 200 \mathrm{~m}$ ) and shallow at the river mouth (Capelli et al., 2007). The discharge rates may vary from typical summer values of the order of $Q_{0}=100 \mathrm{~m}^{3} \mathrm{~s}^{-1}$ to over $2000 \mathrm{~m}^{3} \mathrm{~s}^{-1}$ during some rather exceptional winter episodes. Considering the stream of riverine freshwater within the stagnant coastal waters as a buoyant jet, a crude estimation of $M=Q_{0} U_{0}, B=g^{\prime} Q$, where $g^{\prime}=4 \mathrm{~m} \mathrm{~s}^{-2}$ is the assumed reduced gravity, shows that in all the Tiber discharge conditions $L_{m}$ never exceeds a distance of the order of $10 \mathrm{~m}$. As the horizontal dimension of the ICE-POM grid cells is $O\left(10^{2}\right)$ of $L_{m}$, it can be safely assumed that the single grid cell containing the river mouth may be seen as a "far field" of the buoyant jet from the nearby cells, i.e. a plume. The idea of Oey (1996) was that in such conditions the dominant effect of the buoyancy due to the discharge of freshwater in the river source-cell could be numerically simulated by introducing a negative (downward) vertical velocity pouring a volume of freshwater in the cell but not adding momentum to it. The barotropic mode of the model is then to be adjusted in order to ensure the conservation of mass as $\eta_{t}+\nabla \cdot \boldsymbol{U} D=w_{\mathrm{s}}(x, y, t)$, where $D$ is the total depth $D=H+\eta$, the sum of the bathymetry $H(x, y)$ and the time variable water level $\eta(x, y, t)$, and $\boldsymbol{U}$ is the barotropic velocity. The baroclinic mode of ICE-POM was also modified accordingly, in order to account for the vertical flux of freshwater in the horizontal advection of salinity. Due to the steep salinity gradients generated by the density currents, the time step of the ICE-POM used was reduced to $1.0 \mathrm{~s}$ during significant discharges. The numerical scheme used for the horizontal advection was the classical centered scheme described in Mellor (2004). By reducing the time step, it was possible to use the centered scheme for discharges up to $1000 \mathrm{~m}^{3} \mathrm{~s}^{-1}$, which was the order of magnitude of the maximum discharge in the winter episode here described. In the cases of discharges above this threshold, negative salinity occurred close to the freshwater source and the central scheme had to be replaced by the Smolarkiewicz iterative upstream scheme. This latter method was used to successfully simulate an episode of $1800 \mathrm{~m}^{3} \mathrm{~s}^{-1}$ which occurred in December 2008 (not discussed here).

\subsection{Lagrangian particle dispersion}

A Lagrangian particle dispersion model was applied to the Eulerian ICE-POM velocity fields in order to reproduce the effects of the turbulent transport of passive tracers within the discharged riverine waters. The model used was developed by V. Artale and G. M. Sannino, see García Lafuente et al. (2007). The model is based on the fundamental principle of kinematics, i.e. on the equivalence between Lagrangian and Eulerian velocities:

$\boldsymbol{U}_{\mathrm{E}}(\boldsymbol{x}, t)_{\boldsymbol{x}=\xi(\boldsymbol{A}, t)}=\boldsymbol{V}_{\mathrm{L}}(\boldsymbol{A}, t)$,

where $\boldsymbol{U}_{\mathrm{E}}(\boldsymbol{x}, t)$ is the velocity as defined following the Eulerian point of view at fixed positions $\boldsymbol{x}$ and time $t$, and $V_{\mathrm{L}}(\boldsymbol{A}, t)$, the Lagrangian velocity, is defined as the usual time derivative of the trajectory of the parcel which started at the initial time with label mark (or initial position) $\boldsymbol{A}$ :

$\boldsymbol{V}_{\mathrm{L}}(A, t)=\frac{\partial \boldsymbol{\xi}(\boldsymbol{A}, t)}{\partial t}$.

The trajectories $\boldsymbol{x}(\boldsymbol{t})=\boldsymbol{\xi}(\boldsymbol{A}, t)$ were numerically integrated from the differential Eq. (2) by means of a second-order Runge-Kutta scheme after making use of the equivalence (1).

$\boldsymbol{x}_{n+\frac{1}{2}}=\boldsymbol{x}_{n}+\boldsymbol{u}_{n}\left(\boldsymbol{x}_{n}\right) \frac{\Delta t}{2} \boldsymbol{x}_{n+1}=\boldsymbol{x}_{n}+\boldsymbol{u}_{n+\frac{1}{2}}\left(\boldsymbol{x}_{n+\frac{1}{2}}\right) \frac{\Delta t}{2}+\tilde{\boldsymbol{x}}_{n}$

As shown in Eq. (3), during the first half temporal step (from time $n \Delta t$ to time $\left.\left(n+\frac{1}{2}\right) \Delta t\right)$ only the POM velocity fields $\boldsymbol{u}_{n}$ at the $n$-th time step were used in determining the displacements, while in the second half step (from time $\left(n+\frac{1}{2}\right) \Delta t$ to $(n+1) \Delta t)$ a stochastic contribution $\tilde{\boldsymbol{x}}$ was also considered in order to parametrize the effect of turbulence as a simple random-walk process. The random drift was estimated as

$\tilde{x}_{n}^{i}=\gamma_{n}^{i} \sqrt{2 A K_{n}^{i} \Delta t}$.

In Eq. (4) tensorial notation was introduced for brevity; $x_{n}^{i}(i=1,2,3)$ is the component of the displacement respectively in the $x, y, z$ direction at the $n$-th time step. $\gamma_{n}^{i}$ are 
three real random numbers extracted at the $n$-th time step from a standard normal distribution. The $A K_{n}^{i}$ factors in the random walk process are the horizontal (for $i=1,2$ ) and vertical $(i=3)$ kinematic viscosity as estimated by POM, i.e. by means of the Smagorinsky formulation for the horizontal diffusivity and the Mellor-Yamada scheme for the vertical diffusivity. In the present study all particles started from the same cell in front of the river estuary. The particles released were always non-buoyant and non-decaying, i.e. they represented a conservative tracer neutrally dispersed by the flow. Seeing that the aim of the simulation was to provide a description of the dispersion of passive pollutants associated with the river discharge, a time-dependent number of particles ought to have been released in proportion to the river discharge rate. However, this approach was found to be impractical from the numerical point of view, since the simulations were more than 30 days long, the discharge rate varied considerably in the period, and the hardware capability put a limit on the total number of trajectories which could be tracked. As a consequence, the number of particles released every time step would have been too small to give a clear spatial representation of the dispersal when the river discharge rate was too low. A different strategy was therefore devised: the same number of particles was released at every time step, but the volume of the particles was made proportional to the value of the daily riverine discharge, so that the particles released during episodes of significant discharge contributed more than particles released at other times to the calculation of the concentrations in terms of $\frac{V_{\text {part }}}{V_{\text {cell }} \text {, where } V_{\text {part }} \text { is the total }}$ volume of particles in a cell and $V_{\text {cell }}$ is the volume of the cell. As the distribution of particles was mostly confined to the upper part of the domain (3-4 top cells), the maps of the concentration of pollutants were expressed in terms of mass of pollutants per unit surface. The Lagrangian model was implemented on the same grid and with the same resolution as the POM, the time step used was $300 \mathrm{~s}$. The simulations were made during significant river discharge episodes in both winter and summer conditions. The amount of particles emitted from the source in winter ranged from $33 \mathrm{~kg} \mathrm{~s}^{-1}$ for an average river outflow of $300 \mathrm{~m}^{3} \mathrm{~s}^{-1}$ up to $130 \mathrm{~kg} \mathrm{~s}^{-1}$ in peak discharge conditions.

\section{Satellite, circulation and in situ data}

The diffuse light attenuation coefficient at $490 \mathrm{~nm}$ (K490) fields at $1 \mathrm{~km}$ resolution were obtained by processing the original MODIS AQUA L0 radiance data with the standard SeaDAS software using the SeaWiFS algorithm (Mueller, 2000). K490 is a suitable tracer for riverine discharge and coastal water tracking (Bignami et al., 2007) as it is directly related to the quantity of suspended matter in seawater. Indeed, even though the accuracy of the estimates in Case II (turbid coastal) waters is low, the very high values of this parameter allow for a very good distinction to be made be- tween coastal and open sea waters, in particular for tracking sediment-rich riverine plumes. Therefore, K490 was used here to evaluate the along-shelf and across-shelf penetration of the buoyancy-driven coastal current under different meteorological and hydrological conditions. As regards the wind, several sources of meteorological data were available. The ISPRA tide gauge station at Civitavecchia (onshore, to the NW of the estuary) is a coastal station equipped with standard meteorological sensors operative since August 1986. Since the amplitude of the recorded tidal cycle is typically less than $0.2 \mathrm{~m}$, only the sub-tidal circulation was considered in this study. The wind climate analysis over $20 \mathrm{yr}$ of the time series recorded at Civitavecchia indicated that there are two largely prevailing wind regimes, i.e. northeasterly winds and south-southeasterly winds. The former prevails during winter, having the maximum of the frequency distribution in December-January, the latter dominates in summer and autumn, with maximum of the frequency distribution in summer, but stronger winds $\left(>7 \mathrm{~m} \mathrm{~s}^{-1}\right)$ in autumn. The northeasterly regime has winds directed seaward in the area of the river mouth; the southerly regime favors downwelling. The climatological analysis of the wind at Civitavecchia was compared with the statistics based on the 1971-2000 records at the Fiumicino Airport weather station, which is a WMO reference station run by the Italian company for air navigation services (ENAV). The distributions were found to be very similar. Two years of wind data from the offshore buoy of Civitavecchia were also available from the ISPRA Waves Network (RON). The offshore wind data were reduced to $10 \mathrm{~m}$ height following Kourafalou et al. (1996b) and Hsu (1986). According to the literature (Millot, 1999, 2004; Astraldi and Gasparini, 1992; Artale et al., 1994; Pinardi and Masetti, 2000), the circulation in the central Tyrrhenian Sea is markedly anti-clockwise in winter when it is forced by the inflows of surface MAW from the Western Mediterranean through the Sardinia Channel and by the subsurface Eastern Mediterranean LIW passing through the Sicily channel. In summer and early autumn the circulation is less definite, as the external forcing is extremely reduced. In this period local wind is the main forcing of the regional and local circulation. Tiber river discharge data were available at the hydrological Ripetta station, located in downtown Rome. In the final part of its course toward the sea, the Tiber bifurcates, downstream of the Ripetta station. The main part of the flow, which enters the Tyrrhenian Sea at Fiumara Grande, carries more than 9/10 of the total flow. The other branch, a small artificial channel which has its mouth further north, at Fiumicino, has not been considered here. The bathymetry, the geographical positions of the estuaries and the positions of the meteorological stations are shown in Fig. $1 b$. 

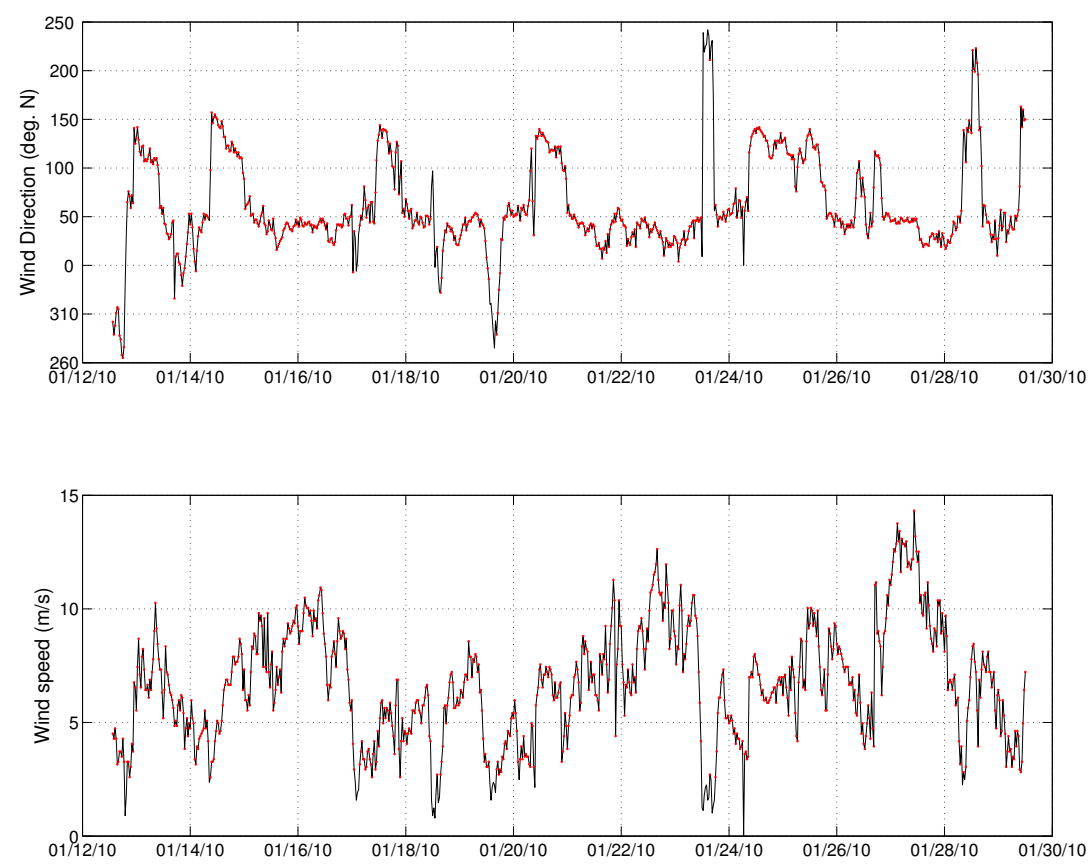

Fig. 2. Wind recorded at the RON buoy of Civitavecchia, 12-29 January 2010. Upper panel: wind direction; lower panel: wind speed. Red dots indicate wind speed greater than $2.5 \mathrm{~m} \mathrm{~s}^{-1}$.

\section{Key studies}

The simulations were made during significant river discharge episodes in both winter and summer conditions. The January 2010 Tiber peak discharge event and the July-August 2010 event are considered here.

\subsection{Winter episode}

The analysis of the wind time series extracted from the available meteorological stations revealed that in the first dekad of January 2010 the wind was southerly-southeasterly, then a calm period followed, and from 12 January on it turned northeasterly, with short southeasterly episodes (Fig. 2) recorded on 13,15, 17, 21 and 25 January due to the transit of small-scale low-pressure systems. Given the orientation of the coast near the Tiber mouth, a southerly wind has a dominant shoreward component and a small component parallel to the coast, thus rendering it slightly favorable to downwelling. The northeasterly wind has an almost completely seaward component, and, finally, the southeasterly wind is downwelling-favorable. Following a period of intense rainfall, on 8 January 2010 an episode of high discharge rate with a daily value of $1187 \mathrm{~m}^{3} \mathrm{~s}^{-1}$ occurred. The discharge rate remained well above the monthly average of $400 \mathrm{~m}^{3} \mathrm{~s}^{-1}$ for more than two days. Due to the cloudiness in the period, clear satellite K490 images were on hand only for 12, 16, 19 and 22 January. The ICE-POM numerical simulation started with a spin-up of 10 days on 22 December 2009; the key study began with the continuous release of Lagrangian particles on
January 1 and ended on 1 February 2010. The results were consistent with the known features of the Tyrrhenian Sea in the winter season. The most recognizable structure in the surface temperature field occuring on 10 January (Fig. 3a), was the deep and widespread cyclonic gyre situated east of the Bonifacio Strait, between Sardinia and Corsica, extending almost to the opposite coast. Also distinctive were the MAW inflow from the western open boundary, apparent in the surface salinity map (Fig. 3b), and the LIW inflow in the Tyrrhenian Sea (shown in the $-300 \mathrm{~m}$ temperature field in Fig. 4a) following the relatively deep $(600 \mathrm{~m})$ trench across the Sicily channel. On a smaller scale, to the northwest of the Tiber river mouth, the local ambient current was affected by the strong jet visible on the northern border of the cyclonic vortex (Fig. 4b). While the speed of the jet reached $0.9 \mathrm{~m} \mathrm{~s}^{-1}$ not far from the eastern coast, the current nearshore was around $0.1-0.3 \mathrm{~m} \mathrm{~s}^{-1}$. According to the numerical simulations, the river plume, clearly visible in the surface salinity map, "hugged" the coast, except for that stretch where the strong jet met the plume. Two days later (12 January), as can be seen from the surface salinity map in Fig. 5a, the interaction of the ambient current with the coastal jet, triggered by the rotation of the wind, extended to the south and was able to detach part of the plume from the coast, stretching it to the northwest.

The results of the Lagrangian particle model for 12 January (Fig. 5b) indicate that most of the pollutants were bounded close to the shore both north and south of the river mouth. However, to the north of the Tiber mouth, some 

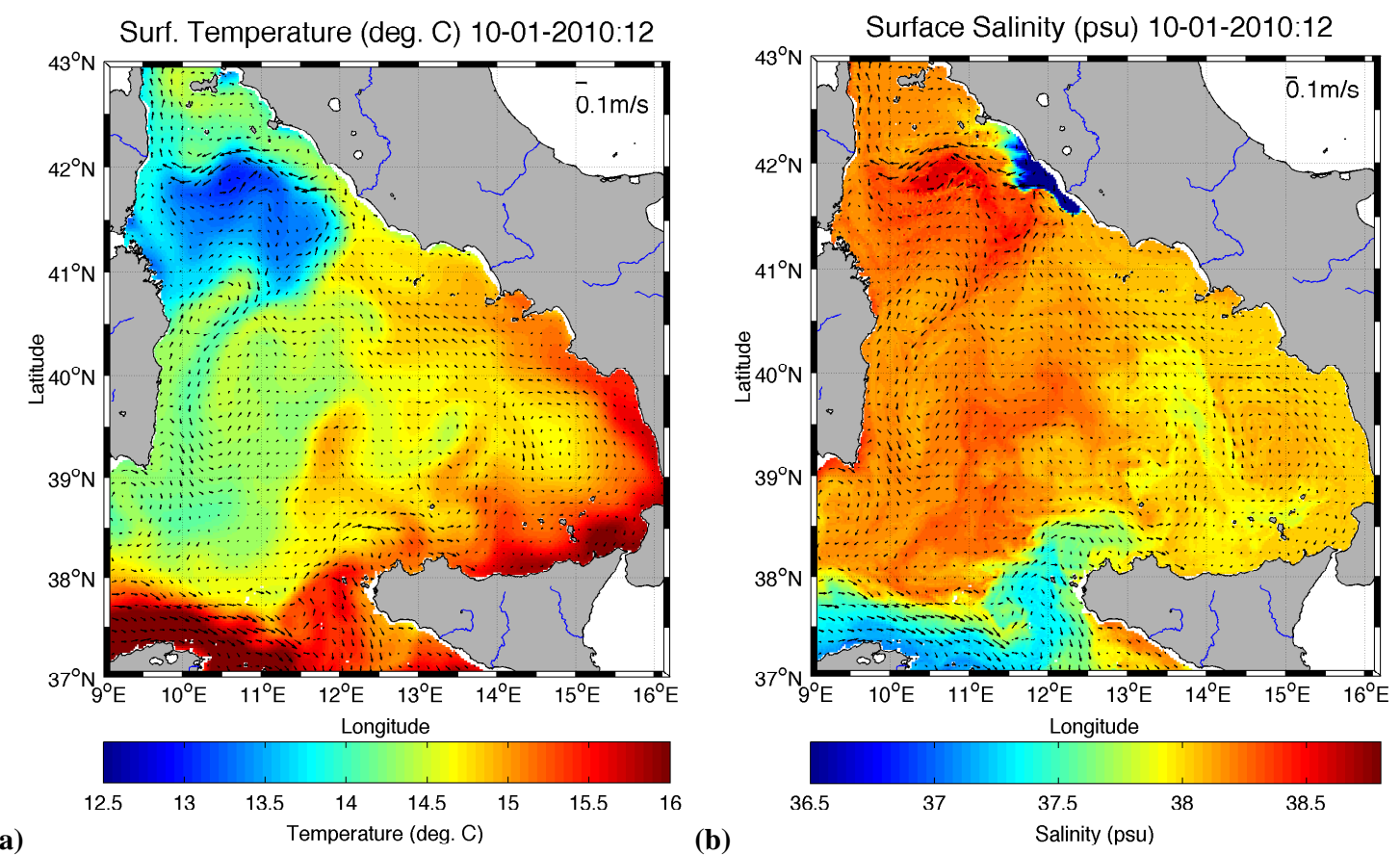

Fig. 3. (a) 10 January 2010 , temperature at $-5 \mathrm{~m}$. (b) 10 January 2010 , salinity at $-5 \mathrm{~m}$.
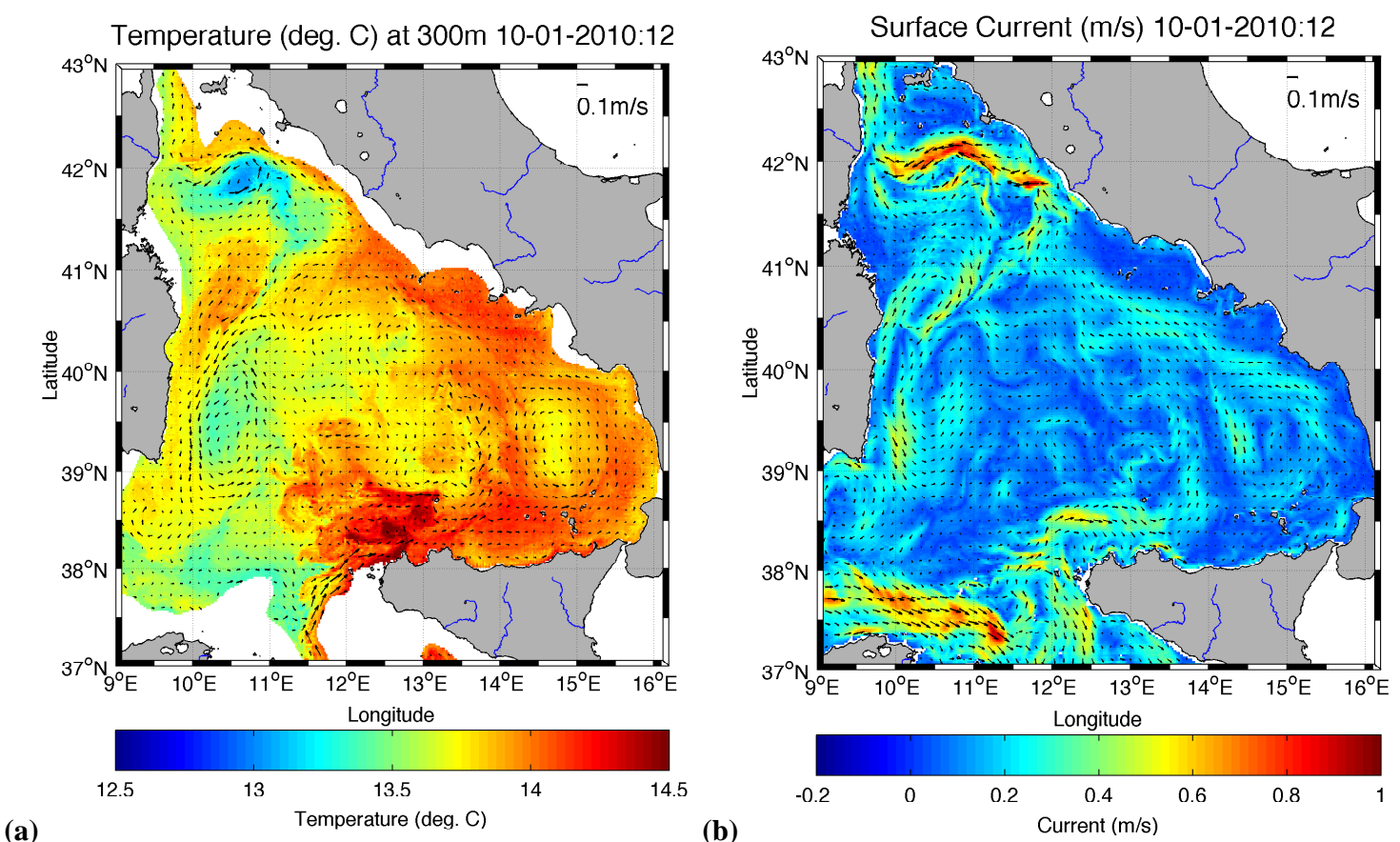

Fig. 4. (a) 10 January 2010 , temperature at $-300 \mathrm{~m}$ (temperature scale is expanded with respect to $5 \mathrm{~m}$ salinity maps). (b) $10 \mathrm{January} 2010$, current at $-5 \mathrm{~m}$.

particles followed the westward low salinity plume seen in the ICE-POM salinity and in the K490 maps. Within the plume, the inhomogeneity of the dispersion of particles was apparent, the stretching of the streaklines of particles offshore being clearly related to the strong current associated to the offshore cyclonic gyre (Fig. 5a), once more emphasizing the role of this open sea feature on coastal dynamics. Even though most of the pollutants were concentrated within the freshwater plume, a significant dispersion on a larger scale in the form of large pools detaching from the main stream 


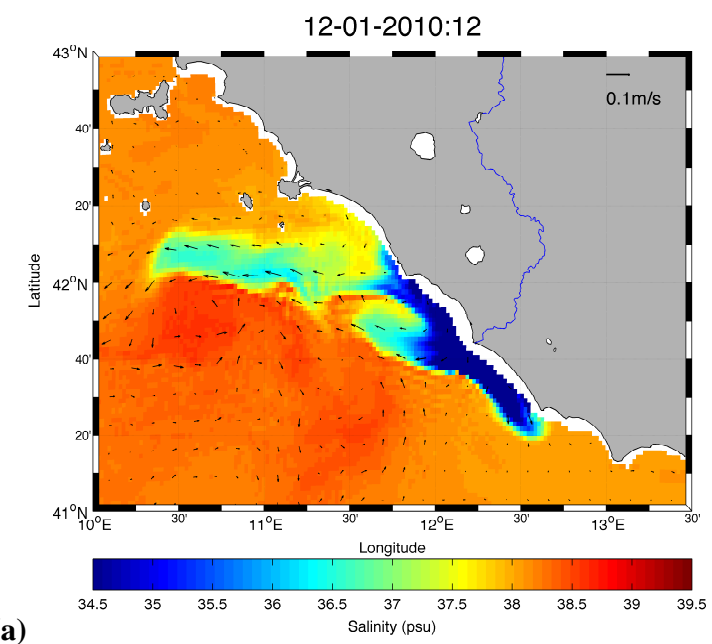

(a)

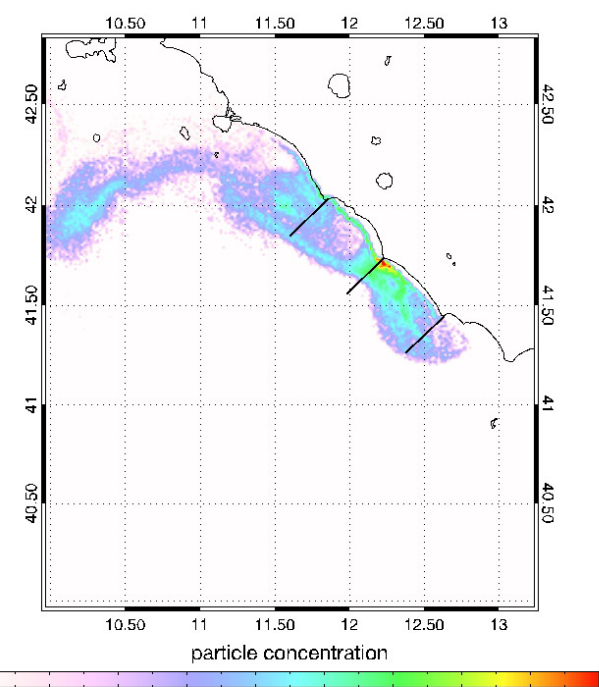

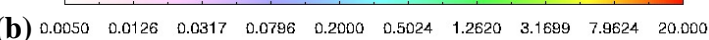

Fig. 5. (a) 12 January 2010, salinity at $-5 \mathrm{~m}$. (b) 12 January 2010 , map of pollutant dispersion; units $\left(\mathrm{g} \mathrm{m}^{-2}\right)$, logarithmic scale.

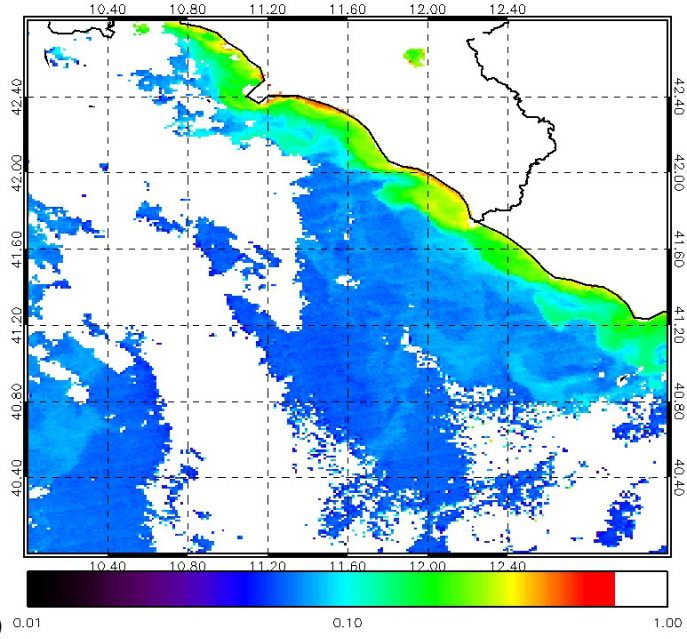

(a) 0.

0.10
.00 (b)

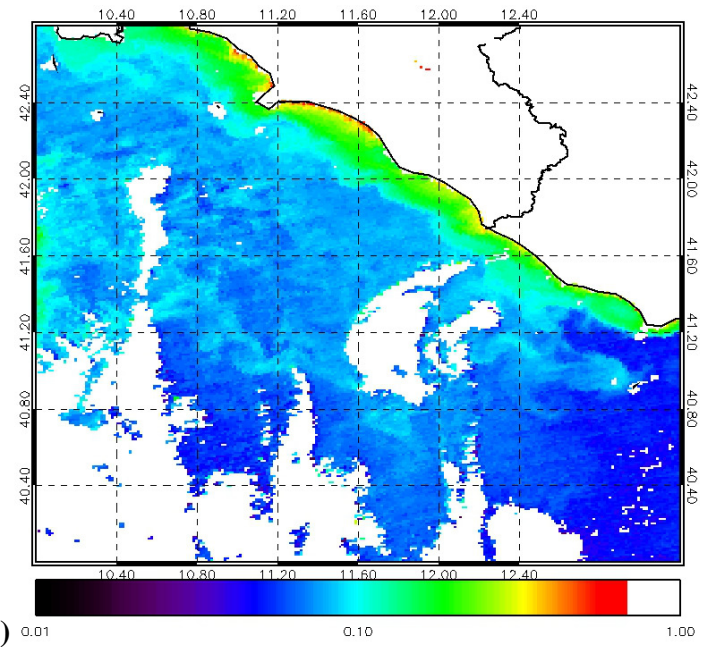

Fig. 6. (a) 12 January 2010, map of K490; units $\left(\mathrm{m}^{-1}\right)$, logarithmic scale. (b) 16 January 2010, map of K490; units ( $\left.\mathrm{m}^{-1}\right)$, logarithmic scale.

was noted from the analysis of the dispersion of the pollutants. The K490 map for 12 January (Fig. 6a) indicated that the Tiber plume had a substantial bulge northwest of the river mouth and that the coastal, turbid flow was directed northwestward, in qualitative agreement with the model results. In particular, the ICE-POM northwestward low-salinity plume, evident in Fig. 5a, was comparable with the high K490 pattern centered at about $42.20^{\circ} \mathrm{N}, 11.20^{\circ} \mathrm{E}$, extending offshore towards the cloud edge (Fig. 6a). Near the coast, to the northwest of the estuary, the width of the pattern of high K490 was narrower than the size of the bulge at the mouth, thus suggesting the presence of a supercritical regime (Fig. 6a). The presence of riverine waters to the south of the Tiber mouth (Figs. 5a, b, and 6a) might have been related to the previous episode of strong discharge that occurred between
8-10 January. In the short period of high discharge rate, the riverine plume might have been in slightly subcritical conditions, returning to supercritical after the episode when the discharge was again close to the monthly average value. The wind might also have played a role. In the first decade of January, the southeasterly wind not only might have directed the freshwater transport towards the shelf break, but could also have induced a coastal Ekman current directed to the south, against the ambient circulation. A similar event was simulated and described by Chao (1988). Of course, the weak but almost continuous distribution of K490 along the coast to the south of the river mouth could also have been related to other possible coastal sources of freshwater in the area, like the coastal lakes and canals of Sabaudia $(80 \mathrm{~km}$ south of the Tiber mouth, not shown). The K490 map for 
16 January (Fig. 6b) was similar to the 12 January map, only smoother. A much smaller width of the river jet-bulge system was observed, probably due to a lowering of the discharge rate, which decreased from the maximum value recorded on the 8 January to $300 \mathrm{~m}^{3} \mathrm{~s}^{-1}$ only a week later. The results of the numerical simulations for 16 January differ from those seen on 12 January in that the plume became almost detached from the coast and stretched offshore due to the strong ambient currents. A study of the wind time series revealed that the speed of the simulated wind had been overpredicted in the previous two days and biased northwesterly, while the offshore buy records at Civitavecchia revealed a weak, steady east-southeasterly wind in the period.

The results of the Lagrangian particle model for 12 January are shown in Fig. 5b. It is apparent that most of the particle concentration is bounded near the shore both to the north and to the south of the river mouth. The plume was detached from the coastline downstream, forming an isolated filament.

\subsection{Summer episode}

On a local scale, the wind was mostly downwelling-favorable in the period 1 July-6 August 2010, changing to upwellingfavorable at least twice. The recordings of the ISPRA RON (offshore) and RMN (onshore) meteorological stations of Civitavecchia clearly indicated the presence of the classical sea breeze superimposed upon the dominant summer southerly wind regime, in agreement with the local climate discussed in Sect. 3. The first episode of northwesterly (upwelling) wind occurred between 16 and 18 July (Fig. 7), briefly interrupting the sea breeze regime. During the following week the prevailing breeze/southerlies regime resumed; then, from the 24th to the 26th, the wind was once again directed northerly-northwesterly. It turned southerly on the 27 th again, but rotated northerly from 31 July to 2 August. The wind speed never exceeded $8 \mathrm{~m} \mathrm{~s}^{-1}$. The river discharge in the period was feeble; the monthly average was around $141 \mathrm{~m}^{3} \mathrm{~s}^{-1}$ and only a weak peak of $217 \mathrm{~m}^{3} \mathrm{~s}^{-1}$ occurred on 31 July. The ten day ICE-POM spin-up started on 22 June. The numerical simulation ran for all of July and the first week of August. The particles were released from 2 July until the end of the simulation on 8 August. In contrast to the winter circulation, the surface current field simulated in July 2010 indicated the sole presence of a moderate northward current on the western boundary of the domain (Sardinia-Corsica border), but no organized current was manifest on the eastern boundary, near the area of interest (see salinity and current map in Fig. 8a). On the large scale some mesoscale activity was still present in the basin, in particular the winter cyclonic vortex near the Bonifacio Strait had developed into in a couple of smaller cyclonic vortices in summer, as described in Artale et al. (1994). However, no dynamical structures had any influence on the eastern coastal circulation in the central Tyrrhenian Sea, leaving the Tiber river plume free of largescale, offshore forcings from the large-scale currents. The dispersion of riverine waters had an essentially local scale, varying rapidly in response of the meteorological forcing. The erratic river plume behavior during the summer episode could be followed using satellite and numerical hindcast as follows. In the period from 12 to 14 July, the southerly surface wind speed did not exceed $5 \mathrm{~m} \mathrm{~s}^{-1}$ (Fig. 7), i.e. was favorable to weak downwelling of the coastal waters. The salinity field (Fig. 8a) and the Lagrangian particle distribution maps (Fig. 8b) confirmed this, indicating freshwater only in a radius of less than $40-50 \mathrm{~km}$ from the river mouth and bounded near the coast. The K490 map for the same day (Fig. 9a) suggested that the river plume was probably even closer to the shore.

From 16 to 18 July, the wind turned northwesterly with speed (offshore) around 5-6 $\mathrm{m} \mathrm{s}^{-1}$, creating the conditions for a moderate upwelling. The detachment of the plume from the coast is apparent from Fig. $9 \mathrm{~b}$ and also from the comparison between the two surface salinity maps for 14 (Fig. 8a) and 18 (Fig. 10a) July. On 18 July the map of particle concentrations generated by the Lagrangian model (Fig.10b) matched the general K490 features, shown in Fig. 9b, in the coastal area and south of the river mouth, but the K490 map clearly indicated the position of the plume propagating southeastwards, while the simulations did not show a similar neat directionality. From 19 to 24 July the southerly summer regime prevailed (Fig. 7), with sea breeze and low winds inducing feeble downwelling. In these conditions, the river plume was confined nearshore again. In the following days, from 24 to 27 July, the wind rotated, keeping between northwesterly and northerly for 3 days with speed (offshore) exceeding $6 \mathrm{~m} \mathrm{~s}^{-1}$. In this period the wind was often parallel to the feeble coastal current and favorable to the upwelling of coastal waters south of the river mouth. The K490 map for 27 July (Fig. 11a) shows that the plume was largely detached from the coast. The formation of upwelling conditions near the Tiber mouth induced by the northwesterly wind can be inferred also from the map of salinity (Fig. 12a). The dispersion of pollutants shown in Fig. 12b was similar to the K490 map near shore, with a large pool of particles emitted during the the preceding days being carried away southeastwards. A similar situation occurred at the beginning of August, as can be seen in Fig. 11b. The transition from downwelling to upwelling was examined in an idealized numerical experiment by García Berdeal et al. (2002), and, in fact, the maps of K490 in Figs. 9b, 11a, b agreed closely with their findings.

\subsection{Comparisons}

The question which naturally arises when dealing with observations and numerical simulations is how reliable the numerical models are in delivering realistic solutions in complex physical situations. In other words, "Are the simulations and the observations comparable?" In the present study there was no simple answer to the question. First of all, quantitative comparison should be made on the same physical quantities; 

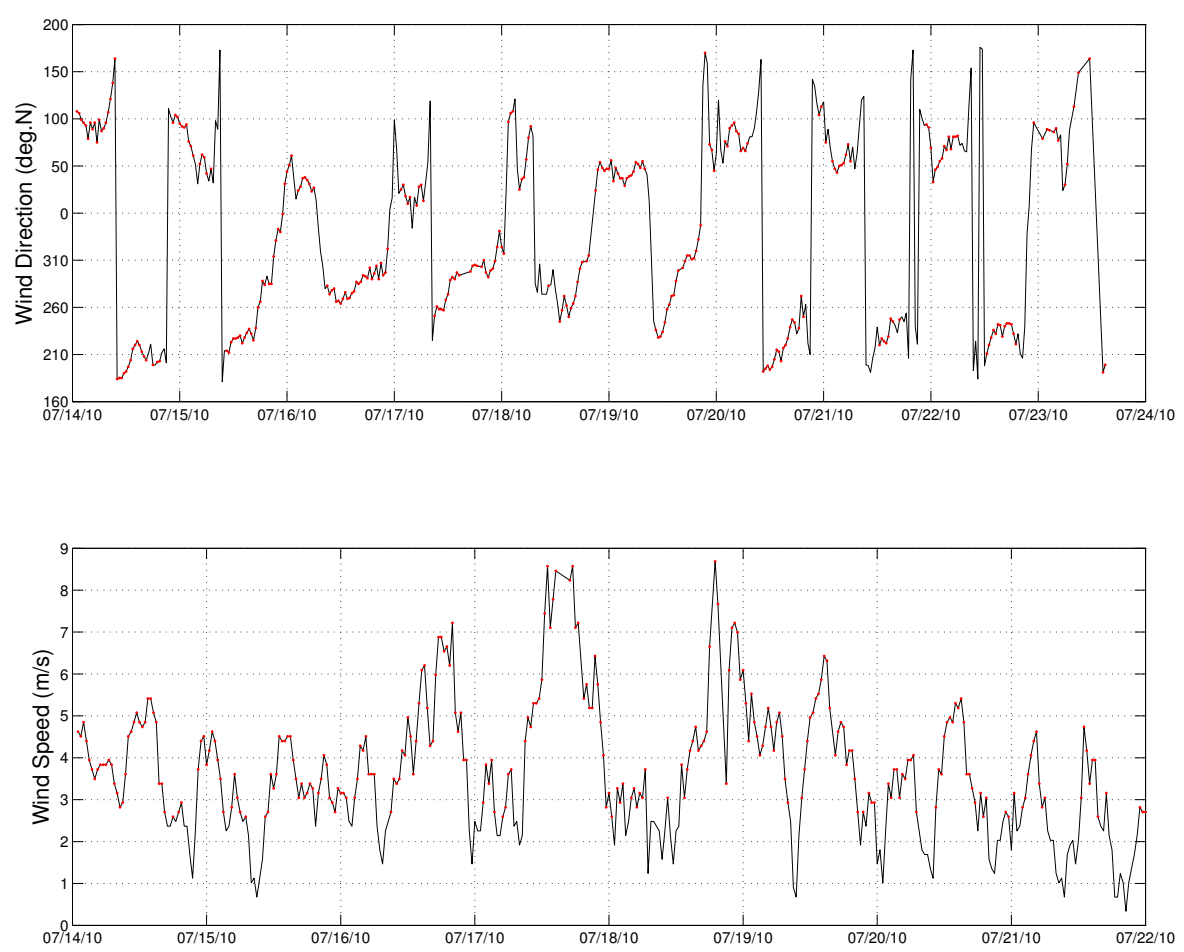

Fig. 7. Offshore wind recorded at the RON buoy of Civitavecchia 14-24 July. Upper panel: wind direction; lower panel: wind speed. Red dots indicate wind speed greater than $2.5 \mathrm{~m} \mathrm{~s}^{-1}$.

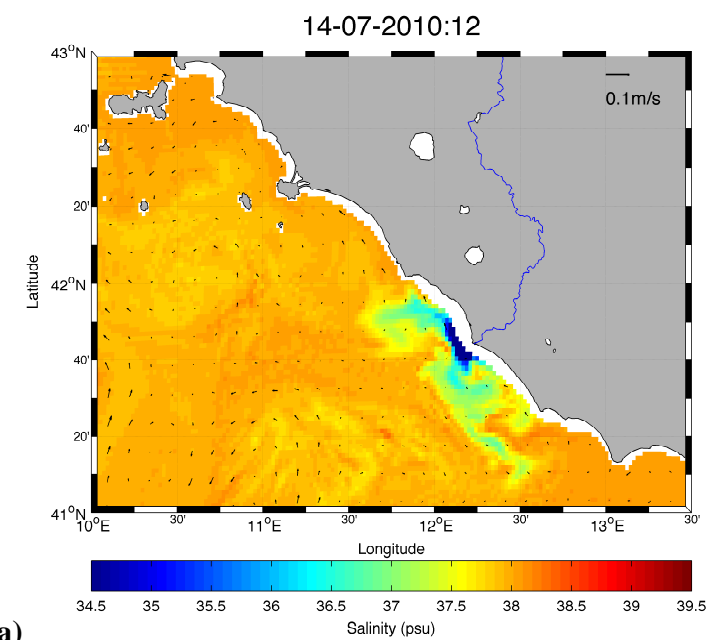

(a)

Fig. 8. (a) 14 July 2010, salinity at $-5 \mathrm{~m}$. (b) 14 July 2010, map of pollutant dispersion; units $\left(\mathrm{g} \mathrm{m}^{-2}\right)$, logarithmic scale.

in the present problem we dealt with three different proxies of the river plume. The time evolution of the field of surface salinity was the closest representation of the dynamics of the riverine waters in coastal areas. Unfortunately, we did not have information about the real salinity, we only had a few snapshots (satellite images) of the attenuation coefficient of the solar radiation at $490 \mathrm{~nm}$. As discussed in Sect. 3, K490 is a very good indicator of the position of the river plume, but the optical properties of the coastal waters depend on many factors like the amount of sediment suspended or the phytoplankton blooms. Both of these are related to the presence of riverine waters, but the river plume is not the only possible cause for their spatial distribution nor for their evolution in time. Even though quantitative analysis was out of our 

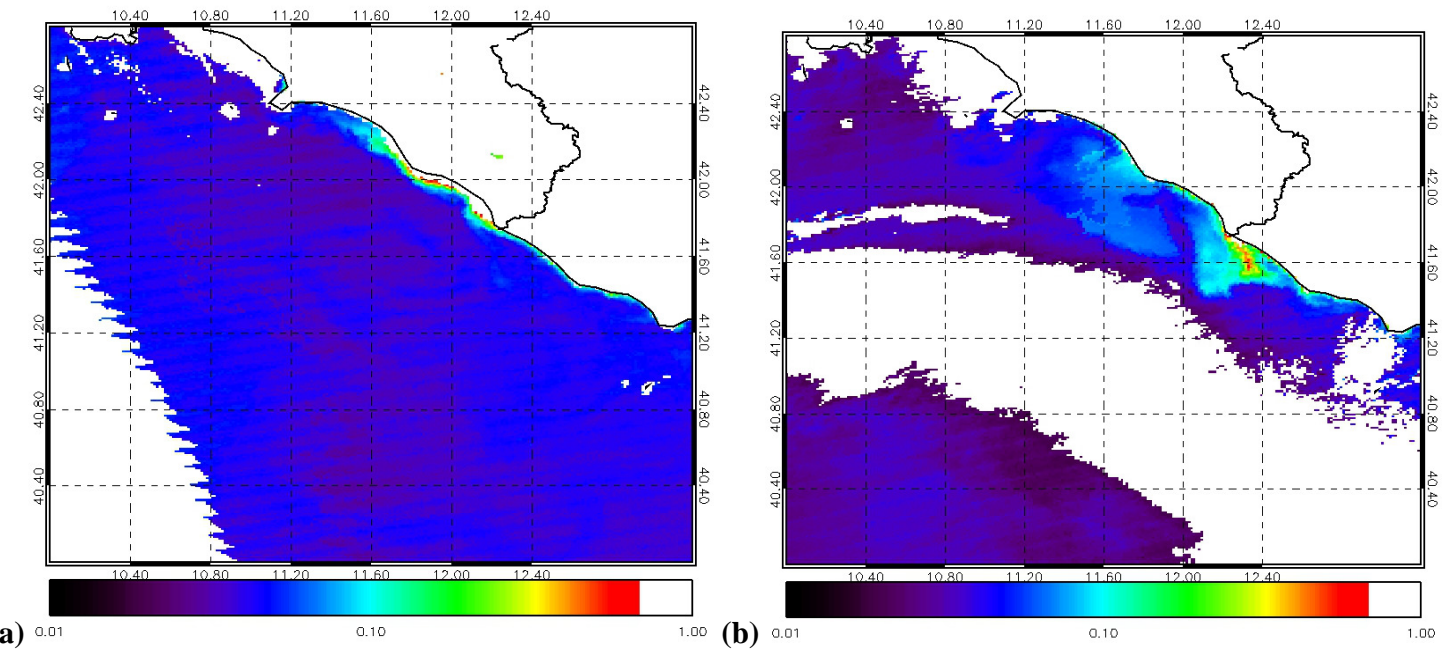

Fig. 9. (a) 14 July 2010, map of K490; units $\left(\mathrm{m}^{-1}\right)$, logarithmic scale.

(b) 18 July 2010, map of K490; units $\left(\mathrm{m}^{-1}\right)$, logarithmic scale.
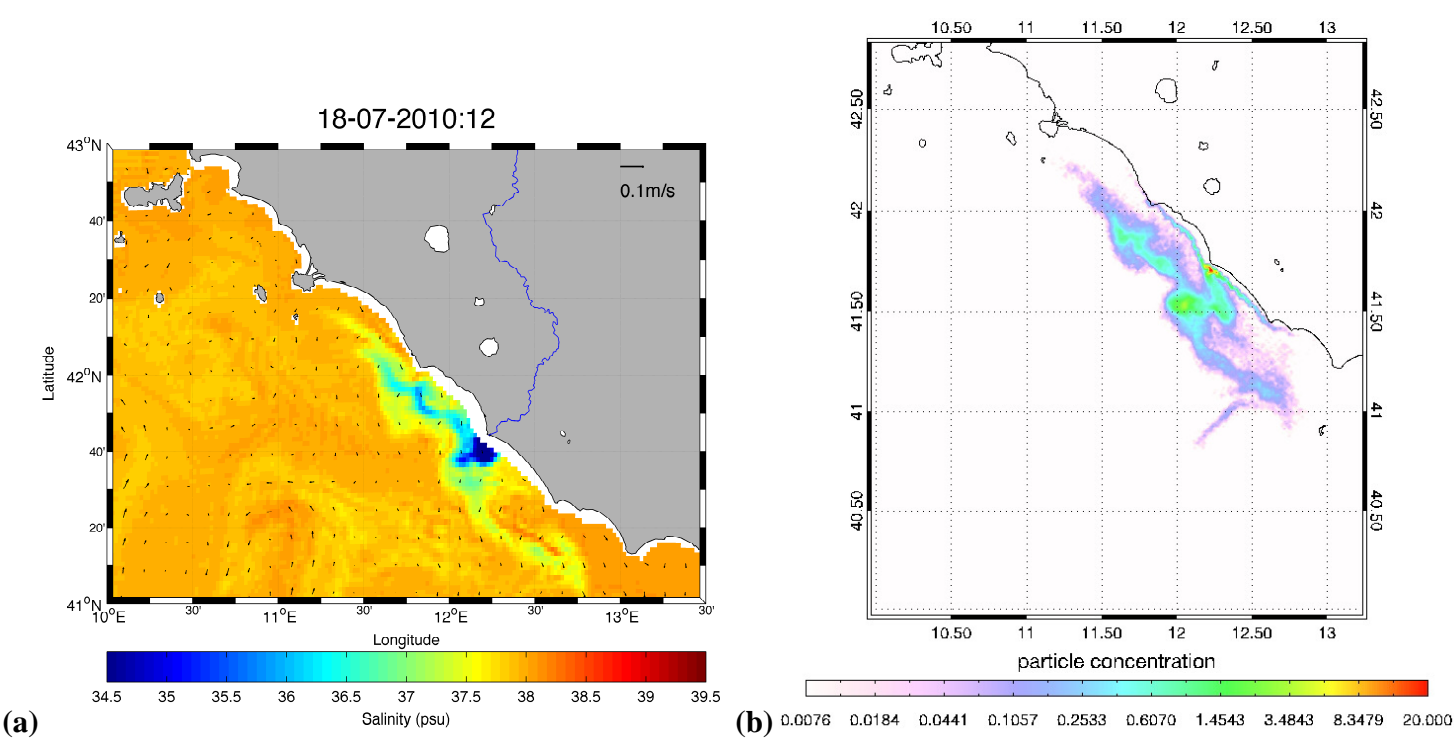

Fig. 10. (a) 18 July 2010, salinity at $-5 \mathrm{~m}$. (b) 18 July 2010, map of pollutant dispersion; units $\left(\mathrm{g} \mathrm{m}^{-2}\right)$, logarithmic scale.

reach, some information could nevertheless be inferred by a semi-qualitative analysis. This approach consisted of the "objective" evaluation in the similarity of the spatial distribution of different fields of K490, surface salinity and pollutant concentrations. The primary concern in the evaluation was the determination of the spatial scale on which to examine the maps. As was seen in the previous section, the scale of dispersion of riverine waters during the winter episode was much larger than the local scale seen in the summer episode. In the analysis of the winter simulation (1-30 January 2010), several spatial parameters were found useful in order to evaluate the quality of the numerical simulations, in particular:

- the position of the extreme values of pollutant concentration/K490/surface salinity; and
- high/low percentiles (indicating presence of plume with high values of K490 and low values of salinity) close to the coast $(1-5 \mathrm{~km})$, offshore $(5-30 \mathrm{~km})$ or far from the river mouth ( $>30 \mathrm{~km}$ from the coast).

The results of the numerical model matched the available satellite maps on 5 days out of 6 , the pattern of pollutant concentration generally being in better agreement with the K490 maps than the salinity. It would perhaps only be fair to consider that in the winter key study, the currents and the dynamical features associated with it and the wind were rather persistent, the river plume being in the configuration "bulge and coastal jet to the north", slowly interacting with the mesoscale dynamical structures. Even if the simulated wind was not always completely aligned with the evolution of the observed wind in following the passage of the meteorological 


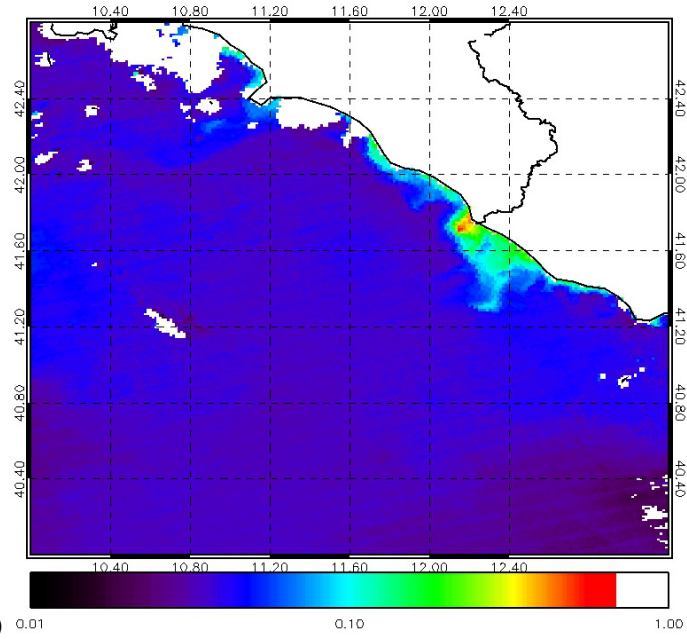

(a) (b)

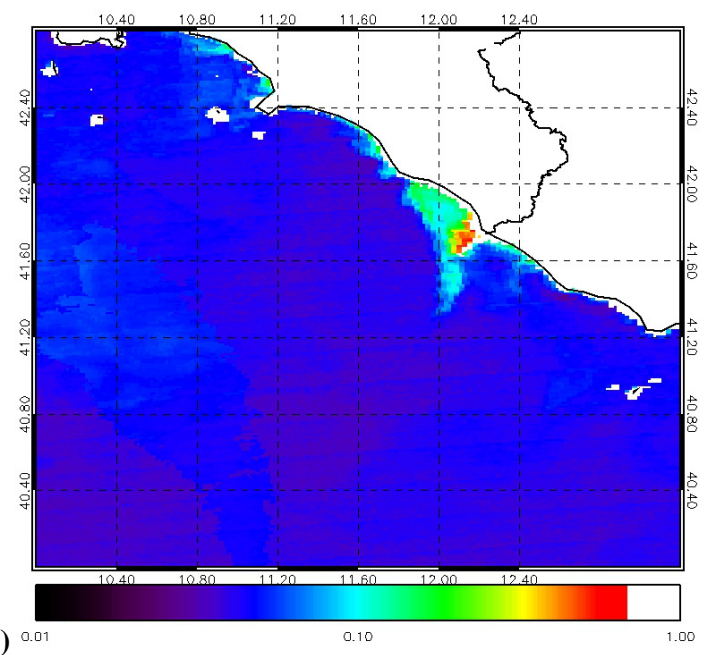

(b) 2 August 2010, map of K490; units $\left(\mathrm{m}^{-1}\right)$, logarithmic scale.
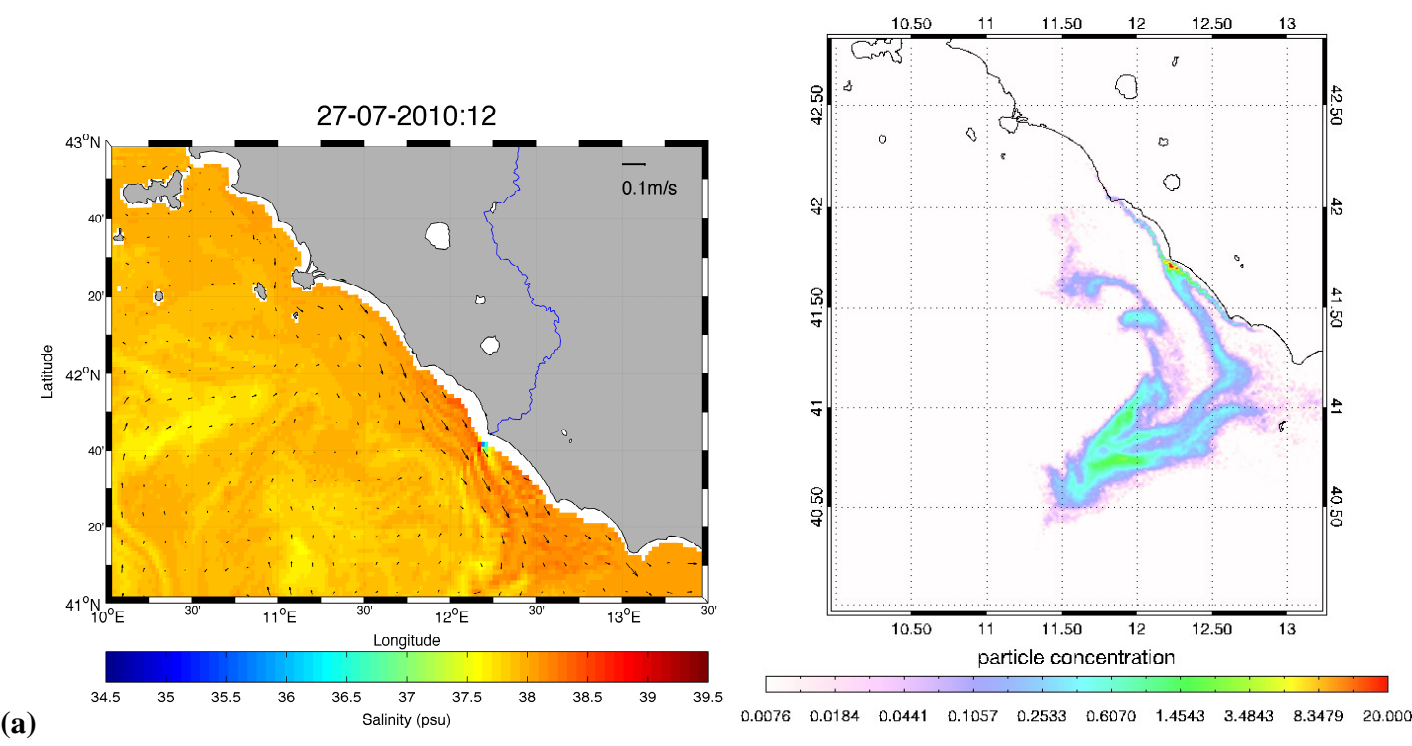

(b)

Fig. 12. (a) 27 July 2010, salinity at $-5 \mathrm{~m}$. (b) 27 July 2010, map of pollutant dispersion; units $\left(\mathrm{g} \mathrm{m}^{-2}\right)$, logarithmic scale.

low-pressure systems, the action of large-scale surface currents generally helped to stabilize the flow. The day showing dissimilar spatial configuration in the considered fields was 16 January, which was discussed in Sect. 4.1.

During the 2 July to 8 August 2010 key study period, there were 23 good quality satellite images to analyze. The features upon which the semi-qualitative analysis on a local scale was based on were:

- the form of the plume near the source and at a radius distance of $20 \mathrm{~km}$; and

- the presence of secondary pools of freshwater/pollutants.

It was found that the agreement between the numerical simulations of surface salinity/Lagrangian particles and maps of
K490 was good in the period 2 July-26 July (13 "good" days out of 15), and relatively poor in the final part of the simulation (26 July-8 August). The concentration of pollutants ranked worse than the surface salinity, mostly due to the presence of secondary pools of particles detached from the main plume in the numerical simulations (see Fig. 12b). A possible explanation for this mismatch is that the Lagrangian particles used to simulate the dispersion were completely neutral, while the sediments carried by the river flow are generally not. This difference in the behavior of the particles became manifest in the case of local dispersion, with low current speed and low turbulence. In the final part of the key study, the moderate northwesterly wind predicted by the meteorological model was slightly overestimated (up to 50\%) from the 28 July to the 5 of August. Even if the upwelling episode 
was substantially reproduced by the numerical model, the overestimate of the wind speed caused the detached plume to be orientated more to the south with respect to its actual position apparent from the satellite maps, and enhanced the formation of large minor pools of low-salinity/pollutants offshore.

\section{Conclusions}

The implementation of a three-dimensional, high-resolution, vertical sigma coordinate model on the Tyrrhenian Sea was effective in reproducing the features of the circulation both in winter and summer conditions. The realistic representation of the mesoscale dynamics in the domain was important for determining the scale of dispersion of the river plume and assessing the importance of the interactions of processes at regional and coastal scales. In particular, it was shown that the riverine water dispersion process can be considered a local coastal problem only in summer, while for the rest of the year it is part of processes occuring on a substantially broader scale of motion. The Tiber river discharge was simulated as a point source of a buoyant plume. This simplified implementation gave satisfactory results in reproducing the main features of the river plume in different environmental conditions. A numerical experiment simulating the release of particles carried by the riverine waters by means of a Lagrangian model gave promising results when compared to satellite maps. Overall, the results indicate that where numerical models are used as an environmental monitoring tool in coastal waters, Lagrangian and Eulerian analyses are complementary in order to have a complete view of many critical situations, like the evolution at sea of pollutant patches of riverine origin, or the effects of spatial distributions of riverine nutrient enrichment in coastal and offshore waters. Semiqualitative analyses were carried out on the spatial distributions of surface salinity, pollutant concentrations and satellite maps of K490 in order to estimate the agreement of the numerical models with the satellite observations. In spite of the difficulty of comparing different physical quantities, some points of agreement could be identified. Results were generally good, in the sense that the spatial and temporal variability of the processes were correctly reproduced in both the key studies. In the January 2010 study, a reason for the agreement between maps of K490 and salinity was largely due to the good quality of the boundary conditions provided by the OPA/MFS model, which paved the way for an adequate representation of the mesoscale dynamics. The wind was an important factor both in the winter and in the summer key studies. In winter, the presence of a large-scale current system mitigated the effects of small differences in direction between observed and simulated wind, while in summer a difference of even a few meters per second in the wind speed (which is, though, not insignificant in summer) affected the position of the plume markedly, and an error in the direction of the wind substantially altered the form of the plume and the dispersion of the pollutants. The high-resolution numerical wind fields used in the present study to force the ICEPOM were barely adequate to give a satisfactory simulation of the riverine-plume dispersion process; it seems like that in order to achieve a better numerical representation of the dynamics, a substantial improvement in both the wind resolution and accuracy would be needed.

On the basis of the results of the key studies and the analysis of the local and regional climatic regimes of wind and currents, an attempt to identify and generalize the principal characteristics of the dispersion of the Tiber freshwater, and the pollutants associated with it, was made.

In winter, due to the prevailing seaward wind regime and the strong ambient currents directed northwestward, the plume "hugs" the coast, forming a well-defined coastal jet directed downstream. As the coastal jet interacts with other dynamical structures under the influence of the meteorological forcings, the plume can be stretched along the coast or be detached from it for distances of more than $100 \mathrm{~km}$. The river plume-Tyrrhenian vortex interaction was found to be an interesting example of how the presence of mesoscale dynamical structures can influence coastal dynamics, making it possible for coastal waters to disperse offshore. In summer, the wind climate is dominated by sea breeze with frequent southerly breaks, the latter creating favorable conditions for weak downwelling. In this season the currents in the eastern boundary of the central Tyrrhenian Sea are very weak and not linked to large-scale patterns, so dispersion conditions are very sensitive to the action of the local wind. In the second key study considered here, the conditions were favorable to downwelling, leading to a confinement of the freshwater of the plume near the river mouth. Only the subsequent turning of the wind to northwesterly allowed moderate episodes of upwelling, which favored the dispersion of riverine waters. Since conditions for a significant accumulation of pollutants near the shore occur frequently in summer, in particular after occasional runoffs, the dispersion of the riverine costal waters critically depends on the action of northwesterly winds, until, in the late season, a basin-scale system of currents is set up again due to re-coupling with the Mediterranean thermohaline circulation.

Acknowledgements. The authors are deeply indebted to Vincenzo Artale, Adriana Carillo and Gianmaria Sannino of ENEA for their many important suggestions concerning the use of POM and for making their Lagrangian particle model available. This work would not have been possible without their full support. Our thanks to Barbara Lastoria of ISPRA for providing and checking the Tiber hydrological data. Many thanks to the INGV and especially to Nadia Pinardi for making the OPA - Mediterranean Forecasting System analysis available.

Edited by: A. Schiller 


\section{References}

Artale, V., Astraldi, M., Buffoni, G., and Gasparini, P.: Seasonal variability of gyre-scale circulation in the northern Tyrrhenian Sea, J. Geophys. Res., 99, 127-137, 1994.

Astraldi, M. and Gasparini, G. P.: The seasonal Characteristics of the Circulation in the North Mediterranean Basin and Their Relationship With the Atmospheric-Climatic Conditions, J. Geophys. Res., 97, 9531-9540, doi:10.1029/92JC00114, 1992.

Bargagli, A., Carillo, A., Pisacane, G., Ruti, P. M., Struglia, M. V., and Tartaglione, N.: An integrated forecast system over the Mediterranean Basin: Extreme surge prediction in the Northern Adriatic Sea, Mon. Weather Rev., 130, 1317-1332, 2022.

Bignami, F., Sciarra, R., Carniel, S., and Santoleri, R.: Variability of Adriatic Sea coastal turbid waters from SeaWiFS imagery, J. Geophys. Res., 112, C03S10, doi:10.1029/2006JC003518, 2007.

Buongiorno Nardelli, B., Tronconi, C., and Santoleri, R.: High and Ultra-High resolution processing of satellite Sea Surface Temperature data over the Southern European Seas in the framework of MyOcean project, Remote Sens. Environ., in press, 2012.

Blumberg, A. F. and Mellor, G. L.: A Description of a ThreeDimensional Coastal Ocean Circulation Model, reprinted from Three Dimensional Coastal Ocean Models, editeb by: Heaps, N. S., American Geophisical Union, Washington DC, 1-16, 1987.

Buzzi, A., Fantini, M., Malguzzi, P., and Nerozzi, F.: Validation of a limited area model in cases of Mediterranean cyclogenesis: surface fields and precipitation scores, Meteorol. Atmos. Phys., 53, 137-153, 1994.

Capelli, G., Mazza, R., and Papiccio, C.: Intrusione salina nel Delta del Fiume Tevere. Geologia, idrologia e idrogeologia del settore romano della piana costiera, Giornale di Geologia Applicata, 5, 13-28, 2007.

Chao, S. Y.: River-Forced Estuarine Plumes, J. Phys. Oceanogr., 18, 1-17, 1987.

Chao, S. Y.: Wind-Driven Motion of Estuarine Plumes, 18, 1-23, 1988.

Fong, D. A. and Geyer, W. R.: Response of a river plume during an upwelling favorable wind event, J. Geophys. Res., 106, 10671084, 2001.

García Berdeal, I., Hickey, B. M., and Kawase, M.: Influence of Wind Stress and Ambient Flow on a High Discharge River Plume, J. Geophys. Res., 107, 3030-3050, 2002.

García Lafuente, J., Sánchez Román, A., Díaz del Río, G., Sannino, G., and Sánchez Garrido, J. C.: Recent observations of seasonal variability of the Mediterranean outflow in the Strait of Gibraltar, J. Geophys. Res., 112, C10005, doi:10.1029/2006JC003992, 2007.

Garvine, R. W.: Estuary Plumes and Fronts in Shelf Waters: A Layer Model, J. Phys. Oceanogr., 17, 1877-1896, 1987.

Hsieh, W. W. and Gill, A. E.: The Rossby Adjustment Problem in Rotating, Stratified Channel, with and without Topography, J. Phys. Oceanogr., 14, 1-14, 1983.

Hsu, S. A.: A Mechanism for the Increase of Wind Stress (Drag) Coefficient with Wind Speed over Water Surfaces: A Parametric Model, J. Phys. Oceanogr., 16, 144-150, 1986.

Kourafalou, V. H., Oey, L. Y., Wang, J. D., and Lee, T. N.: The fate of river discharge on the continental shelf 1 . Modeling the river plume and the inner shelf coastal current, J. Geophys. Res., 101, 3415-3434, 1996a.
Kourafalou, V. H., Oey, L. Y., Wang, J. D., and Lee, T. N.: The fate of river discharge on the continental shelf, 2. Transport of coastal low-salinity waters under realistic wind and tidal forcing, J. Geophys. Res., 101, 3435-3455, 1996b.

Mellor, G. L.: Users guide for a three-dimensional, primitive equation, numerical ocean model, Princeton University, Princeton, NJ, 56 pp., 2004.

Mellor, G. L. and Jamada, T.: A Hierarchy of Turbulence Closure Models for Planetary Boundary Layers, J. Atmos. Sci., 31, 17911806, Corrigendum, 34, p. 1482, 1974.

Millot, C.: Circulation in the Western Mediterranean Sea, J. Mar. Syst., 20, 423-442, 1999.

Millot, C. and Taupier-Letage, I.: Circulation in the Mediterrean Sea, The Handbook of Environmental Chemistry, Vol. 1 (The Natural Environment and the Biological Cycles), SpringerVerlag, 2004.

Morel, A. and Prieur, L.: Analysis of variations in ocean color, Limnol. Oceanogr., 22, 709-722, 1977.

ueller, J. L.: SeaWiFS algorithm for the diffuse attenuation coefficient, $K(490)$, using water-leaving radiances at 490 and $555 \mathrm{~nm}$, in: O'Reilly, J. E. and co-authors: SeaWiFS Postlaunch Calibration and Validation Analyses, Part 3, edited by: Hooker S. B. and Firestone, E. R., NASA/TM-2000-206892, NASA Goddard Space Flight Center, Greenbelt, Maryland, 11, 24-27, 2000.

Oddo, P., Adani, M., Pinardi, N., Fratianni, C., Tonani, M., and Pettenuzzo, D.: A nested Atlantic-Mediterranean Sea general circulation model for operational forecasting, Ocean Sci., 5, 461-473, doi:10.5194/os-5-461-2009, 2009.

Oey, L. Y.: Simulation of Mesoscale Variability in the Gulf of Mexico: Sensitivity Studies, Comparison with Observations, and Trapped Wave Propagation, J. Phys. Oceanogr., 26, 145-175, 1996.

Oey, L. Y. and Mellor, G. L.: Subtidal Variability of Estuarine Outflow, Plume and Coastal Current: A Model Study. J. Phys. Oceanogr., 23, 1-8, 1992.

Palma, E. D. and Matano, R. P.: Dynamical impacts associated with radiation boundary conditions, J. Sea Res., 46, 117-132, 2001.

Pinardi, N. and Masetti, E.: Variability of the large scale general circulation of the Mediterranean Sea from observations and modelling: a review, Palaeogeogr. Palaeocl., 158, 153-173, 2000.

Pinardi, N., Allen, I., Demirov, E., De Mey, P., Korres, G., Lascaratos, A., Le Traon, P.-Y., Maillard, C., Manzella, G., and Tziavos, C.: The Mediterranean ocean forecasting system: first phase of implementation (1998-2001), Ann. Geophys., 21, 3-20, doi:10.5194/angeo-21-3-2003, 2003.

Speranza, A., Accadia, C., Casaioli, M., Mariani, S., Monacelli, G., Inghilesi, R., Tartaglione, N., Ruti, P. M., Carillo, A., Bargagli, A., Pisacane, G., Valentinotti, F., and Lavagnini, A.: POSEIDON: An integrated system for analysis and forecast of hydrological, meteorological and surface marine fields in the Mediterranean area, Nuovo Cimento, 27C, 329-345, 2004.

Vetrano, A., Gasparini, G. P., Molcard, R., and Astraldi, M.: Water flux estimates in the central Mediterranean Sea from an inverse box model, J. Geophys. Res., 109, C01019, doi:10.1029/2003JC001903, 2004. 